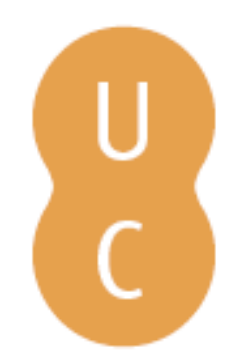

\title{
pommalina
}

\section{Algumas considerações históricas e historiográficas sobre os documentos da hermética arábe medieval}

\author{
Autor(es): $\quad$ Alfonso-Goldfarb, Ana Maria \\ Publicado por: Imprensa da Universidade de Coimbra \\ URL \\ persistente: URI:http://hdl.handle.net/10316.2/31303 \\ DOI: $\quad$ DOI:http://dx.doi.org/10.14195/978-989-26-0241-7_3 \\ Accessed : $\quad$ 26-Apr-2023 11:16:51
}

A navegação consulta e descarregamento dos títulos inseridos nas Bibliotecas Digitais UC Digitalis, UC Pombalina e UC Impactum, pressupõem a aceitação plena e sem reservas dos Termos e Condições de Uso destas Bibliotecas Digitais, disponíveis em https://digitalis.uc.pt/pt-pt/termos.

Conforme exposto nos referidos Termos e Condições de Uso, o descarregamento de títulos de acesso restrito requer uma licença válida de autorização devendo o utilizador aceder ao(s) documento(s) a partir de um endereço de IP da instituição detentora da supramencionada licença.

Ao utilizador é apenas permitido o descarregamento para uso pessoal, pelo que o emprego do(s) título(s) descarregado(s) para outro fim, designadamente comercial, carece de autorização do respetivo autor ou editor da obra.

Na medida em que todas as obras da UC Digitalis se encontram protegidas pelo Código do Direito de Autor e Direitos Conexos e demais legislação aplicável, toda a cópia, parcial ou total, deste documento, nos casos em que é legalmente admitida, deverá conter ou fazer-se acompanhar por este aviso.






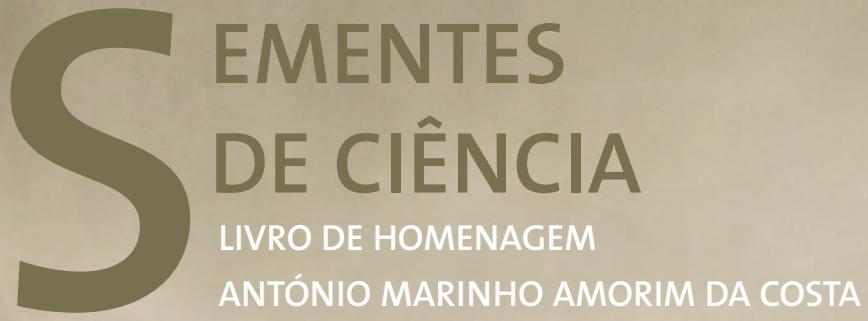

Sebastião J. Formosinho Hugh D. Burrows EDITORES 
Ana Maria Alfonso-Goldfarb

Coordenadora do Centro Simão Mathias de Estudos em História da Ciência

Professora do Programa de Estudos Pós-Graduados em História da Ciência da PUC-SP

Honorary Research Fellow Univ. College London

III.

\section{ALGUMAS CONSIDERAÇÕES HISTÓRICAS \\ E HISTORIOGRÁFICAS SOBRE OS DOCUMENTOS \\ DA HERMÉTICA ÁRABE MEDIEVAL}

Há pouco menos de duas décadas, mais precisamente em 1992, minha equipe e eu, tivemos o imenso prazer de conhecer pessoalmente o Prof. Amorim da Costa. Vários colegas e amigos portugueses haviam nos falado muito, e sempre boas coisas, sobre esse destacadíssimo seguidor do Prof. Gouveia. E, não por acaso, a esse coro juntou-se também nosso mestre, agora saudoso, Prof. Debus. Com essas credenciais distinguidas, não tivemos dúvidas em enviar-lhe um dos primeiros convites para a grande sessão dedicada à História da Ciência, da qual participaria cerca de meia centena de estrangeiros, durante o Congresso América 92: Raízes e Trajetórias (São Paulo-Rio de Janeiro).

Conforme já mencionamos, porém, conhecê-lo de perto superou qualquer expectativa: estudioso dedicado, vivaz e sem preconceitos; figura simpática e generosa como deveriam ser todos os mestres. Enfim, dono de qualidades ímpares que o tempo e a convivência futura só confirmariam.

Mas seria, ainda, naquele primeiro encontro cheio de surpresas, de 1992, onde descobri que tínhamos em comum um interesse pouco difundido, até então, entre os historiadores da química: a documentação alquímica e seu complexo e mal entendido trabalho. Assim, a melhor forma de homenagear esse grande Professor e querido amigo, será trazer aqui um pouco da temática que foi objeto de uma de nossas primeiras conversações...e acredito ainda seja um ponto de interesse comum. 
A complexidade da documentação hermética em língua árabe

Ao longo dos séculos, copistas, estudiosos e, por fim, editores dedicaram especial atenção aos documentos herméticos e alquímicos medievais, escritos em língua árabe. No final do século XIX, entretanto, M. Berthelot criticaria esse longo e árduo trabalho de edição e estudo dos textos árabes, dizendo que:

"Les auteurs de ces publications, imbus des illusions alchimiques, se sont attachés surtout aux théories et doctrines mystiques, de préférence aux faits positifs, et ils ont autorité sous ce rapport; ne se préoccupant guère ni des dates de ces écrits et des découvertes contemporaines qu'ils peuvent effectivement contenir, ni de la réalité des attributions faites à tel ou tel auteur, célebre dans la tradition." ${ }^{1}$

A seleção dos textos árabes, organizada por Berthelot, assim como as inúmeras notas, onde incluiu paralelos com a química de sua própria época, tornam evidente que os "fatos positivos" e as "descobertas efetivas" estariam (ou desembocariam) nos trabalhos de laboratório ali contidos ${ }^{2}$.

No entanto, Berthelot, que nada sabia de árabe, introduziu suas densas observações e notas sobre documentos inteiramente traduzidos por M. Houdas, que nada sabia de química. Essa combinação pouco recomendável, tanto no que diz respeito a aspectos filológicos quanto da história da ciência, foi muito criticada por estudiosos futuros ${ }^{3}$.

Entre esses críticos, porém, irá continuar a busca de "fatos positivos" na documentação alquímica produzida no Mundo Árabe medieval. Uma busca que gerou trabalhos preciosos, como os de J. Ruska e seu grupo de estudiosos, ou ainda os de H. E. Stapleton e E. J. Holmyard. Mas também uma busca que levou esses estudiosos a uma série de becos sem saída quando tratavam de concepções e procedimentos nada "positivos" ou modernos... algo, aliás, bastante freqüente nos documentos alquímicos. Basta lembrar, por exemplo, que Stapleton, autor de um dos melhores e mais completos trabalhos sobre o laboratório árabe medieval, viu-se em palpos de aranha ao tentar definir em termos modernos os procedimentos de destilação ali mantidos ${ }^{4}$. E, assim, poderíamos ir enumerando muitos outros exemplos. 
Alguns deles inclusive já retomados e melhor definidos pela historiografia contemporânea ${ }^{5}$.

Nossa pequena contribuição aqui vai nesse sentido e refere-se a um procedimento que foi dos mais indigestos, desde o séc. XIX, nos estudos sobre o laboratório alquímico árabe: a transmutação da matéria. Será utilizada para esse fim a cópia escurialense do Livro do Tesouro de Alexandre, tratado hermético anônimo, provavelmente escrito no século X pelo (pseudo) sabeans de Harran ${ }^{6}$.

Embora essa obra esteja repleta de segredos de ofício e muitas outras dificuldades, sua aparência de mero receituário nos permitirá uma análise convencional dos processos até chegarmos ao lapis philosophorum para o qual toda análise desse tipo seria inócua. Nossa aproximação será feita a partir da primeira referência à transmutação existente no texto que só acontece nos últimos capítulos da segunda parte, dedicada ao trabalho alquímico e metalúrgico:

"Capítulo sobre $<<$ a transmutação do cobre de sua aparência para a aparência do ouro > e sua forma. ${ }^{7}$ Este capítulo é dos mais valorizados pelo rei Hermes. Saiba que os corpos que mais merecem ser transmutados na forma de ouro são a prata e o cobre. Isso porque a prata se mistura com o ouro e vice-versa sem que um provoque no outro alterações ruins e sem fazê-lo perder suas qualidades. Prevalecerá a cor daquele que for colocado em maior quantidade, pois ambos são equivalentes em situação de mistura, e o tempo em que a prata derrete é igual ao tempo em que o ouro derrete sendo esta mais uma harmonia da Natureza.

O cobre, dos sete Corpos, é o mais parecido com o ouro quanto à cor; o tempo que leva para derreter é mais perceptível e está apto para misturar-se com o ouro, mas de maneira inferior à prata -ou seja, do que a mistura desta com o ouro- pois torna o ouro seco e quebradiço. Por isso, a prata tornou-se mais próxima da natureza do ouro do que o cobre. O cobre, por sua vez, tem a qualidade da //ffl. $19 \mathrm{v})$ cor vermelha, além de aceitar a cor de ouro puro, de uma forma visível, pois do cobre sai o chabah de boa cor dourada, simplesmente ao se jogar sobre ele a tutya. 
"É importante, como disse Hermes a respeito, que seja tutya purificada, manipulada corretamente como exige a sabedoria, pois [quando] vertida sobre o cobre purificado, o transformará em ouro"s.

A palavra em árabe para "transmutação" (naql) ocorre aqui, pela primeira vez, exatamente quando se fala sobre o processo para obtenção de um material com "aparência e forma" de ouro, ainda que processos semelhantes de transformação entre metais tenham acontecido, com freqüência, anteriormente na obra.

Trata-se de uma receita singular, pois o cobre aparece como um corpo base para a obtenção de ouro, enquanto na maior parte dos textos alquímicos esse papel cabe ao chumbo. Entretanto, embora rara, essa inversão não seria exclusiva do L.T.A.. Num de seus estudos, Stapleton analisa um texto alquímico atribuído à figura lendária de Agathodaimon e talvez, como o L.T.A., escrito por (pseudo) sabeans de Harran, em que o cobre, ao invés do chumbo, será matéria-prima da transmutação. Segundo Stapleton, a presença do cobre seria um índice da antigüidade da alquimia, já que este era o metal mais usado antes do chumbo se tornar conhecido e popular 9

É possível, assim, que tanto no tratado de Agathodaimon quanto no L.T.A., existam reflexos de uma documentação datada de uma época na qual se mantinham conhecimentos ainda pertencentes à idade do Cobre.

Por outro lado, a correspondência, no L.T.A., entre o cobre transmutado ao ouro e o chabah (ou "cobre amarelo"10) oferece indicações de que se trata do "ouro-cobre" ou do "cobre-dourado" de Plínio, ou seja, o latão. Conforme é bem sabido, na antigüidade, parte das ligas de cobre foi considerada tipos de bronze. Algumas destas seriam semelhantes ao que hoje se chamaria de bronze, e outras ao latão ${ }^{11}$. Receitas de "cobre amarelo" semelhantes a aqui presente entrariam nos conhecimentos do século $\mathrm{X}$ árabe. ${ }^{12}$ Mas há casos onde o chabah aparece tanto como constituinte quanto como produto dessas receitas. Isso indica que diversos materiais foram conhecidos sob essa mesma denominação entre os árabes ${ }^{13}$.

De forma semelhante, a tutya, outro dos componentes importantes da receita acima, teria sido o nome dado a compostos de zinco, obtidos in natura, como o sulfeto, o carbonato e o silicato desse metal, além de seu óxido - que há muito eram recolhidos das paredes das fornalhas e das 
chaminés, combinados com traços de outros óxidos e metais. O zinco metálico, que também entraria neste compósito, somente passa a ter menções após o século XIII ${ }^{14}$ - muito embora noutro ponto do L.T.A. seja utilizado um material conhecido como "ferro chinês" (darsini) que seria exatamente o zinco em sua forma metálica.

Em todo caso, segue a esta receita uma para "purificação" da tutya que nada acrescenta ao já estudado - muito embora na seqüência apareça pela primeira vez o termo "elixir" incorporado ao receituário, este venha diretamente relacionado a "tutya purifica"15.

"Purificação do cobre que se deseja sublimar. Resfria-o em azeite de oliva 49 vezes e a seguir em água amolecedora, ou seja, //(fl. 20v) 49 vezes como mencionei [que se fizesse] com [o azeite de] oliva, e depois resfria-o com água de sangue 21 vezes. Esse é o cobre purificado, [que servirá] para o que se segue.

Sessão: Saiba que a tutya purificada é um elixir magnífico, que muda a aparência do cobre para ouro no que se refere à sua cor, ao seu brilho, à sua resistência e à sua maleabilidade. Isso porque se jogares o peso de 5 Dirhams dele sobre 20 Dirhams de cobre, este se tornará ouro puro, do qual não duvidará quem o vir. Guarda, pois, este capítulo e protege-o, porque ele é dos conhecimentos mais valiosos e dos capítulos mais nobres." 16

Assim como a "transmutação", o "elixir" só aparece junto aos processos relacionados à obtenção do ouro. Muito embora seja possível notar que esta receita é apenas um ensaio ou "diversão" dos autores do L.T.A., pois as proporções e materiais usados dariam apenas um bom e maleável latão próprio para a bijuteria.

De todo modo, a receita seguinte, embora menos pretensiosa, dá mais o que pensar:

"Capítulo sobre a purificação da prata separando-a, por fundição, do estanho em fogo forte, sendo isto [tão] famoso em todos os tempos e nações que não há necessidade de mencioná-lo [aqui]."17 
Era comum em obras alquímicas considerar a natureza do estanho como próxima à da prata e tomar como base esta relação para manipular os dois minerais ${ }^{18}$. O processo aqui descrito, assemelha-se ao da obtenção da prata metálica por copelação. Ao invés do minério de estanho, minério de chumbo contendo prata seria usado nesse processo, conhecido há muito tempo e descrito por Plínio ${ }^{19}$. Resta dizer que, em outros pontos do L.T.A., "dois chumbos" (chumbo e estanho), confundidos em outras obras alquímicas, são distinguidos com clareza ${ }^{20}$. A confusão específica na receita acima pode ter sido fruto de engano na compilação das fontes ou, quem sabe, um erro proposital para confundir os não iniciados. Em todo caso, se até aqui receitas simples apresentaram problemas, imagine-se agora, ao iniciar-se o conjunto de procedimentos que levarão ao lapis philosophorum, conforme veremos abaixo:

"Capítulo sobre o elixir da prata que a transmuta na cor do ouro.

Quatro são os princípios de que necessita esse elixir: o primeiro princípio será o fundamento. Pega 2 Mithqals de limalha de ouro e 2 Mithqals de limalha de prata; de sal amoníaco, //(fl. 21r) 2 Mithqals; e de enxofre amarelo, um Mithqal; moe tudo sobre uma salaya com vinagre de vinho até tudo ficar fino. Depois, verte sobre isso 5 Dirhams de mercúrio e amassa tudo muito bem por um dia e uma noite. Coloca num cântaro de cerâmica ou num frasco de vidro e sela com argila da sabedoria. Ponha num atanor enquanto a Lua estiver no trígono de Júpiter e sem estar de face para nenhum dos dois maléficos. Passadas sete horas, retira o conteúdo do frasco e guarda-o; isso será o fundamento."21

O fundamento ou base seria uma espécie de primeiro princípio do "grande elixir" ou lapis philosophorum. Este seria o primeiro de quatro "princípios" que podem estar relacionados aos presentes nas obras herméticas de autores como Jabir e (pseudo-) al-Majriti que consideravam o sexto nível de composição das naturezas, o nível em que, dos três reinos da Natureza, obtém-se quatro princípios manipuláveis. Tais princípios seriam: "a tintura; a terra; o óleo e a água”. ${ }^{22}$ Assim, o primeiro princípio seria formado a partir de sementes preciosas de ouro e prata e, ao menos, um "espírito", 
entre aqueles que foram os principais "espíritos" para quase toda a alquimia árabe: enxofre, sal amoníaco e mercúrio. ${ }^{23}$ No caso presente, teríamos a "Tintura", parte essencial da "pedra", responsável pela coloração da matéria ao conter sementes de ouro e prata e os três "espíritos". De igual maneira, é possível notar nos princípios que se seguem a mesma idéia de processo ou manipulação:

"O segundo princípio. Pega da boa limalha de cobre vermelho 5 Mithqals; de rusukhataj, [que é] cobre calcinado, 2 Mithqals; moe fino e acrescenta à limalha, moendo tudo com água de toronjas e 2 Dirhams de sal amoníaco por um dia e uma noite. Rega com vinagre sublimado e acrescenta um Dirham de sal amoníaco. Moe por um dia e uma noite - além da primeira - seca à sombra e guarda." ${ }^{24}$

A relação ouro, prata e cobre, conforme já referido anteriormente, parece se repetir agora nos "princípios". Parece coerente que o cobre, que foi o "corpo" utilizado em quase todos os "capítulos" anteriores surja aqui como uma espécie de "princípio" corpóreo. Pensando na relação entre os quatro princípios derivados dos três reinos, teríamos, a "Terra", ou seja, o princípio corpóreo. Como já aconteceu anteriormente, o princípio que se segue será simplesmente a descrição de um processo:

"O terceiro princípio. Pega do enxofre amarelo 5 Mithqals e joga-o sobre 15 de prata pura, ainda líquida, //(fl. 21v) até calcinar. Depois moe [tudo]. Se sobrar algo que não calcinou, retorna ao fogo até que [tudo] derreta e joga em cima enxofre amarelo o suficiente para que [a mistura] calcine. A seguir, moe com a água na qual se deposita a força de Marte por um dia e uma noite. Acrescenta a isso cobre calcinado, limalha de prata e limalha de cobre, de cada, 2 Mithqals; sal amoníaco, 3 Mithqals; e rega com a essência marciana citada. Moe por um dia e uma noite e seca na sombra." 25

É provável que este princípio deva ser entendido como uma seqüência na cadeia de importantes relações que parece se delinear, conforme avança 
a descrição de cada princípio. Pois chama a atenção o insistente calcinar da matéria argentífera com auxílio da "força" queimante do enxofre, para depois tratá-la com a "força" recuperadora da água de Marte - usada anteriormente no L.T.A. para remover a "secura" dos metais. "Mortificar" a matéria -enegrecendo-a para depois "revivificá-la" e remover seu negrume- seria um dos mais antigos e conhecidos "princípios" alquímicos da transmutação. A uma base corpórea cúprica contendo prata -signo do metal a ser transmutado - se agregariam a "revivificante" água marciana e o sal amoníaco ${ }^{26}$, que para alguns alquimistas seria, ao mesmo tempo, uma "água" limpante unificadora das partes. Em relação aos quatro princípios obtidos a partir dos três reinos, este possivelmente seria o "Óleo", ou seja, o princípio queimante. Naturalmente o quarto e último princípio refere-se a procedimentos envolvendo a "água" no sentido alquímico:

"O quarto princípio. Pega de limalha de prata e de limalha de cobre, de cada uma, 2 Mithqals; moe isso apenas com água de sangue sublimada-sem o sal amoníaco - e acrescenta 5 Mithqals de mercúrio, moendo tudo muito fino até ficar bem misturado. Verte por sobre: de sal amoníaco, 1 Mithqal; de bórax, 1 Mithqal; de cinábrio, 1 Mithqal, moe [até ficar] fino, por um dia e uma noite. Assa em fogo brando por sete horas, moe e rega com a quarta água. Deixa secar na sombra e rega com a água chamada triras o quanto puder ser tolerado, moendo todo o tempo //(fl. 22r). Seca à sombra e depois rega com a quarta água outra vez. Seca exatamente 3 vezes e depois [torna] a secar. Quando a Lua estiver ligada a Júpiter de modo aceitável e este estiver ocupando um chifre [da Lua] na sua casa ou quando estiver exaltado, junta esses quatro princípios sobre o fogo -e que seja esse fogo brando- e rega-os com óleo de ovo, extraído por corcubita e alambique. Coloca tudo num frasco e sela com argila da sabedoria, deixa secar, e assim por diante 3 vezes. Recoloca sobre fogo moderado por sete horas, na medida da força do fogo [existente no] cinábrio . [Ao] retirá-lo, encontrarás o Todo: uma Pedra vermelha que tende um pouco ao negro. Este é o grande elixir. Guarda-o então e dá graças inúmeras à Causa Primeira e ao Movedor do Mundo que te agraciou e te guiou neste êxito" 27. 
Este quarto princípio parece estar diretamente ligado à grande "água aguda", triras, insistentemente usada para constituí-lo. Por outro lado, em parte anterior do L.T.A., a quarta grande "água" se caracteriza por incluir as demais "águas agudas", potencializando, numa perspectiva sempre alquímica, as propriedades destas. Limpantes e desagregadoras, essas "águas" concentrariam em triras a capacidade para a "dissolução", ou mais especificamente, a "purificação" da matéria. A "purificação", por sua vez, pode ser pensada mais como um princípio essencial da obra alquímica do que como um mero processo eventual desta. A quarta "água” representaria uma espécie de fonte ou veículo máximo da "purificação"28, completando o conjunto de quatro princípios retirados dos três reinos.

Embora a diversidade de processos torne a receita difícil de interpretar, a coloração vermelha escura de seu produto final nos leva a considerar a presença do cloreto de ouro para o qual seria necessária uma quantidade ínfima do precioso metal. Essa hipótese, entretanto, só seria viável se, durante os múltiplos processos para se obter o lapis philosophorum, ocorresse a produção da água régia, algo perpetuamente sob questionamento em História da Química.

Mas, contrariando muito do que se diz sobre a descoberta da água régia, R. C. Thompson considera que ela já era provavelmente conhecida entre os assírios que a utilizaram para obter o cloreto de ouro, usado na coloração do vidro vermelho rubi - presença, aliás, constante em seus formulários ${ }^{29}$. O salitre, em todo caso, peça central nos debates sobre a antigüidade da água régia, era certamente um velho conhecido dos povos mesopotâmicos. ${ }^{30}$

Em todo caso, a "Pedra vermelha", ou "grande elixir", foram desde sempre sinonímias do lapis philosophorum, ou seja, a famosa pedra filosofal que, segundo se acreditava, promoveria a definitiva, porque mais verdadeira, transmutação. É verdade que alguém como Ar-Razi, por exemplo, parece ter montado seu discurso sobre a transmutação sem incluir a "pedra única"31. Todavia na obra jabiriana, o "grande elixir" encontra um lugar especial. Conforme vimos acima, formado também por "quatro princípios", esse "grande elixir" seria o mais verdadeiro, pois surge, dentre três processos alquímicos descritos, naquele em que ocorreria a transmutação plena ${ }^{32}$. 
Contudo, se os "três processos" lembram os "três elixires" que o índice do Tesouro de Alexandre anunciou; ou ainda se os quatro princípios da obra jabiriana parecem os mesmos presentes na segunda parte do L.T.A., ${ }^{33}$ essas comparações podem ser problemáticas. Os "quatro princípios", para Jabir, correspondem aos princípios ou bases elementares: terra, fogo, água e ar, sobre os quais nenhuma referência explícita pôde ser verificada no texto do Tesouro de Alexandre. Neste, todavia, os quatro princípios derivados dos três reinos parecem corresponder às etapas do processo alquímico aqui concentradas no lapis philosophorum.

A esse respeito, F. W. Zimmermann ${ }^{34}$, estudioso da hermética e do pensamento árabe medieval lembra que entre os pensadores adeptos ao Kalam no século IX a idéia dos quatro elementos era rejeitada.

Do mesmo modo, caberia ainda lembrar que, entre os séculos XVIII e XIX, outra vez, a composição da matéria será explicada a partir de processos e não de elementos ${ }^{35}$. De tal sorte que, ao menos na aparência, os processos de laboratório descritos no L.T.A. manteriam essa mesma estrutura. Não esqueçamos, porém, que estamos lidando com procedimentos e materiais relacionados a antigos e reservados segredos de ofício. Compará-los diretamente àqueles obtidos em laboratórios setecentistas e oitocentistas, como fez Berthelot, pode levar a enormes equívocos.

Por outro lado, apesar das críticas feitas a Berthelot e da conseqüente substituição de seu método (retomando, mais uma vez, a vertente do trabalho filológico), os resultados continuaram nada animadores. Assim, para melhor entender e, quem sabe, superar essa série de questões, vale a pena observar mais de perto suas implicações historiográficas, apenas indicadas brevemente até o momento.

Breve revisão historiográfica envolvendo a documentação sobre hermética árabe e suas fontes.

Conforme indicado, as principais questões historiográficas vistas acima, não tiveram origem recente. Todavia, essas questões adquiriram mais peso a partir das primeiras décadas do século xx. Aproximadamente nessa época, 
H. Stapleton fará uma ampla busca para encontrar as fontes que teriam dado origem à documentação medieval em árabe sobre hermética e alquimia/ química. Seus esforços como arabista e historiador da química tinham dois propósitos. O primeiro deles era retomar, como centro de seus estudos, as regras filológicas tradicionais para fixação, tradução e análise dos textos árabes ${ }^{36}$. O segundo estava ligado a um sério problema para a história da química: encontrar a nascente original de processos, materiais e conceitos presentes nesses textos, mas sem paralelo na documentação clássica e da antigüidade $\operatorname{tardia}^{37}$.

O trabalho de Stapleton produziria uma série de traduções e estudos importantes. Em nenhum deles, porém, conseguiu comprovar, de forma evidente, as fontes originais mais antigas. De fato, em seus estudos aos tratados medievais árabes, Stapleton apenas indica um pequeno número de palavras e expressões que, segundo ele, poderiam ter sofrido influência de remotas fontes chinesas, mesopotâmicas e egípcias. Aliás, os materiais e processos, que arqueólogos e filólogos modernos diziam encontrar-se nessas fontes documentais antiqüíssimas, sempre foram para Stapleton a base sobre a qual o laboratório medieval árabe adquirira consistência, bem como características próprias ${ }^{38}$.

Assim, em um de seus últimos grandes trabalhos, já na década de 50, Stapleton admite que embora fosse patente o conhecimento de antigos textos e receituários entre aqueles que produziram a documentação em língua árabe, os rastros históricos desse caminho continuavam pouco visíveis e ainda precisavam ser averiguados devidamente. Seus muitos levantamentos sobre a manipulação da matéria e o uso do laboratório apenas lhe haviam dado a certeza da enorme antigüidade dessas práticas ${ }^{39}$.

Um outro trabalho, de dimensão similar e feito em paralelo ao de Stapleton, seria desenvolvido por J. Ruska, também reconhecido por sua excelência enquanto arabista e historiador da química. Como Stapleton, mas com maior detalhe e precisão, Ruska rastrearia a documentação do que se considerou como a primeira hermética em língua árabe, onde havia um grande número de ideias e receituários alquímicos/químicos ${ }^{40}$.

Ruska deu início a uma escola de arabistas e historiadores da química e produziu, como ninguém antes, uma vasta coleção de análises que desafiavam 
o previamente estabelecido sobre as origens e influência da documentação alquímica em língua árabe. Assim, por exemplo, em um de seus artigos, dedicado ao estabelecimento de um método para eliminar da história da química velhas idiossincrasias, irá sugerir que o problemático nó entre a alquimia árabe e aquela de tradição grega fosse desatado devidamente. Esse método não era outro senão o da crítica textual, utilizado desde sempre pelos filólogos e até mesmo pelos historiadores da química antiga, mas desenvolvido com um rigor próximo ao científico. Segundo ele, tal seria a forma de eliminar os problemas que envolveram esses estudos desde seu início moderno, a partir do século XIX, devido às pré-concepções típicas da época. Sem deixar de agradecer àqueles responsáveis por esse início, assim como pela vasta documentação descoberta, Ruska lembra o enfoque equivocado que a maioria deles dedicou aos trabalhos medievais em língua árabe ${ }^{41}$.

Desta forma, um grande número dos trabalhos de Ruska e de seus associados teria como função sanar as falhas em estudos anteriores sobre o tema. Vários aspectos centrais à alquimia árabe do medievo, bem como sua influência e assimilação no mundo cristianizado constituíram o foco principal desses trabalhos. Ruska dedicaria, por exemplo, mais de quinze anos de estudo a Razes e seus importantes trabalhos de laboratório. Esse bem conhecido médico e alquimista do século x árabe teria sido autor de textos que não apareciam sob seu nome; enquanto outros lhe eram atribuídos erroneamente. Ruska faria um amplo levantamento dessa documentação, comparando famílias de manuscritos e complementando aqueles com partes faltantes através, inclusive, de traduções latinas posteriores ${ }^{42}$.

É possível, no entanto, que devido à amplitude desse e de outros trabalhos de Ruska - ou à eterna dificuldade de encontrar as fontes da documentação alquímica em árabe - seu ambicioso projeto de usar a crítica textual de modo quase científico nunca atingiu as expectativas. Apesar de Ruska e seus colaboradores terem colocado os trabalhos do laboratório medieval árabe, definitivamente, no mapa da história da química, suas análises tiveram que se apoiar, muitas vezes, apenas em pressupostos. De maneira especial, no que dependia da localização e verificação das fontes mais antigas, seu trabalho trouxe poucos resultados efetivos. Da mesma forma que Stapleton, 
Ruska atribuía fontes antiqüíssimas à alquimia árabe, mas nunca conseguiu qualquer comprovação sólida ${ }^{43}$.

Todavia, a origem e o caminho histórico dessas fontes remotas interessavam não apenas aos arabistas. Outros historiadores da ciência e da técnica, como W. Ganzenmuller, envolvidos na averiguação dos processos de laboratório e suas origens tiveram o mesmo problema. Uma das questões centrais no período (e até hoje mal resolvida) relacionava-se a descobertas arqueológicas de materiais sofisticadíssimos que teriam pertencido a antigas civilizações.

Em especial, as escavações feitas em sítios pertencentes a antigas culturas mesopotâmicas estavam no fulcro desse dilema ${ }^{44}$. Em primeiro lugar, essas escavações haviam revelado, por exemplo, vidros e esmaltes coloridos, ligas e metais tratados, além de outros materiais, que seriam fruto de processos desconhecidos tanto pelas culturas clássicas quanto da antigüidade tardia. Como desconhecidos pareciam ter sido também, com algumas exceções, entre os medievais latinos. Além do mais, sabia-se que tais processos haviam sido motivo de sigilosos estudos e enormes debates até muito depois de originada a ciência moderna ${ }^{45}$.

Em segundo lugar, essas escavações geraram problemas entre os arqueólogos e os filólogos dedicados ao tema. Os materiais encontrados requeriam um estudo detalhado, não só quanto a sua composição (que era da alçada dos arqueólogos), mas para verificar como se dera sua manipulação e identificação em épocas tão remotas (que era da alçada dos filólogos). Os documentos que pareciam trazer essas referências eram receituários difíceis de ler ou interpretar, pois de maneira geral estavam em tabletes cuneiformes, muitas vezes quebrados e/ou semi-apagados e, com certa freqüência, em um único exemplar ou cópia. Era, portanto, quase impossível cobrir as falhas, saltos e faltas desses textos e ainda fazê-los coincidir com as receitas esperadas. Mas como as evidências materiais eram muito fortes, tomou-se a via contrária: sobre os textos alquebrados e faltosos foram introduzidos termos e expressões das receitas esperadas pelos estudiosos modernos ${ }^{46}$.

Naturalmente, as conseqüências desse método pouco recomendável não foram das melhores. Usar esses textos como fontes ou acompanhar seu caminho até documentos de épocas posteriores quase sempre trazia 
poucos resultados e muitas críticas. Inicia-se a partir desse impasse uma lenta e interminável revisão dos documentos mesopotâmicos, causando um descompasso entre o trabalho filológico e o arqueológico, refletido no campo até hoje. Com os estudos filológicos em perpétua revisão, continuaria difícil aplicá-los como base para encontrar correspondências entre a documentação mesopotâmica e aquelas de épocas posteriores. Além disso, o imenso lapso de tempo até que essas fontes voltassem, ao menos aparentemente, a se manifestar durante o medievo, deixou uma única certeza: a surpreendente antigüidade de certos materiais e manipulações, já indicada pelos arqueólogos e assumida por autores como Stapleton e Ruska ${ }^{47}$.

Mas, conforme já mencionado, esse era um dilema que envolvia não só assiriólogos e arabistas, mas todo historiador da ciência e da técnica cujo trabalho implicasse, de algum modo, a verificação de fontes materiais e documentais muito antigas. Entre eles estava W. Ganzenmuller, que, na década de 30, produziu uma série de estudos nos quais, entre outras coisas, buscava alternativas para solucionar o impasse. Diferente de outros autores, num desses estudos, Ganzenmuller diz não haver certeza se alguns dos materiais produzidos entre os mesopotâmicos equivaleriam, ou não, aos de épocas posteriores e que serviam como modelo comparativo para as averiguações. Desta forma sugere, como possível solução, a volta a um duro trabalho de laboratório que buscasse reproduzir as receitas da documentação antiga e medieval para verificar quais eram, de fato, os materiais ali obtidos ${ }^{48}$.

Como vimos no caso de Berthelot, sugestões como a de Ganzenmuller não eram uma novidade entre os historiadores da ciência. Mas os documentos de hermética e alquimia, com seus textos extremamente difíceis e vocabulário cifrado, continuariam a dar poucas brechas para esse tipo de intento. Da mesma forma vista acima no caso do L.T.A., esses textos diziam respeito a materiais, processos e objetivos distantes dos modernos e, na maioria das vezes, resistiam a interpretações ou reprodução de seus receituários em laboratório ${ }^{49}$.

Assim, após décadas de tentativas e interpretações anacrônicas, em um estudo que se tornaria central para a história da química, produzido durante os anos 60, o então jovem pesquisador, A. Debus propõe uma saída diversa. Primeiramente, descreve os caminhos historiográficos seguidos até então. 
Desta forma, identifica os problemas mais sérios no tratamento da documentação para história da química, sobretudo a de cunho hermético e alquímico. Um dos primeiros problemas seria o constante descarte de tudo que não parecesse caber em parâmetros modernos, que teria deixado de fora partes constituintes dessa documentação e, portanto, vitais para compreendê-la. Outro problema, de igual importância, estaria ligado às tentativas freqüentes de estudar, a partir do laboratório moderno, seus procedimentos e preparados, pois mesmo as realizadas por químicos experientes tiveram pouco sucesso ${ }^{50}$.

Debus conclui dizendo que as tentativas de análise tradicionais acabariam quase sempre frustradas, pois não tocavam nem de longe a enorme complexidade de textos como os alquímicos. Abandonar a perspectiva moderna e assumir esses textos a partir da perspectiva oferecida por seus próprios autores seria, para Debus, a única forma de analisá-los. Segundo ele, a partir desse novo ângulo, seria possível verificar, quase de imediato, algo de suma importância para qualquer análise: o sentido dado a textos alquímicos por seus autores foi muito mais amplo do que hoje atribuímos à química moderna. Segue daí que, a compreensão desses textos não poderia depender exclusivamente de parâmetros químicos atuais, mas dependeria de buscas mais amplas em outros campos ${ }^{51}$.

Quais fossem esses outros campos e parâmetros, a obra frutífera de Debus respondeu, pelo menos, no que tange a alquimia renascentista e a química da primeira modernidade ${ }^{52}$. Adaptar esse modelo aos documentos de outras épocas e lugares, buscando entender o que seus autores disseram dentro de seu próprio contexto, tem sido parte das pesquisas desenvolvidas pelo CESIMA ${ }^{53}$, através de um mapeamento das transformações históricas dos estudos sobre a matéria ${ }^{54}$. Assim, processos antigos de laboratório, como os presentes no L.T.A., passam a ser mais bem entendidos em seu próprio contexto, a partir de sua inserção relacional, num mapa maior de estudos congêneres (através da averiguação de fontes e/ou das mudanças e permanências de conceitos e parâmetros em diferentes épocas) mesmo que continuem a resistir a verificações estritamente modernas. 


\section{Referências}

${ }^{1}$ M. Berthelot, La chimie au Moyen Âge, vol I, reimpr. da ed. 1893 (Osnabrück/Amsterdam, O. Zeller/Philo Press, 1967), pp. 3-4.

${ }^{2}$ A seleção de textos árabes e as notas a estes, feitas por Berthelot, encontram-se no vol. III da obra supracitada.

${ }^{3}$ Para exemplo, vide E. J. Holmyard, "A critical examination of Berthelot's Arabic chemistry", Isis, vol. VI, 1924, pp. 479-99.

${ }^{4}$ Esse trabalho envolve várias memórias longas; o problema específico, acima citado, encontra-se em Stapleton et al, "Chemistry in Iraq and Persia in the Tenth Century" Mem. Asiat. Soc. Bengal. VIII: 6, 1927, p. 328 et seq; questão semelhante pode ser encontrada em J. Ruska, Al-Razi's Buch Geheimnis der Geheimnisse in: Quel Stud. Ges. Nat. Med, vol VI, Berlim, 1937, p. 73 et seq.

${ }^{5}$ Vide, por exemplo, S. N. Haq, Names, Natures and Things (Dordrecht/ Boston/ Londres, Kluwer, 1994), que retoma questões da obra de P. Kraus sobre o Corpus Jabiriano; ou ainda K. C. Ryding, "Islamic Alchemy according to al-Khawarizmi", Ambix XLI: 3, 1994, pp. 121-134, que retoma questões sobre procedimentos de laboratório existentes nesta obra e anteriormente analisados por Stapleton; sobre a destilação, vide M. H Roxo Beltran, Imagens de magia e de Ciência: entre o simbolismo e os diagramas da razão (São Paulo: Educ/FAPESP, 2000); ou ainda meu pequeno estudo "O legado árabe para a ciência da matéria entre os séculos IX e XI", in Anais do V Sem Nac. de Hist. da Ciência, (São Paulo, SBHC), pp. 30-4.

${ }^{6}$ Essa cópia, traduzida pela Profa. Safa A. A. C. Jubran e por mim, foi centro de um longo estudo que realizei sobre esse tipo de obra, vide meu Livro do Tesouro de Alexandre; um estudo de hermética árabe na oficina da história da ciência (Petrópolis, Vozes, 1999); a partir daqui iremos nos referir a esse documento como L. T. A.

${ }^{7}$ No texto original existem vários trechos escritos em código. Porque aqui não era pertinente, tal marcação foi retirada.

${ }^{8}$ L.T.A. fls. $19 \mathrm{r} / \mathrm{v}$.

${ }^{9}$ Vide em H. E. Stapleton, "The Antiquity of Alchemy", Ambix, Vol. V:1/2, pp. 25-8.

${ }^{10}$ fl. 36r, fl. $41 \mathrm{v}$.

11 Vide Plínio, Natural History. Reimp., 10 vols, Loeb Classical Library Cambridge (Mas.)/(Londres, Harvard University Press/ William Heinemann), Livro XXXIV, Caps. 2 e 20.

12 Vide, por exemplo, M. Berthelot, op. cit., Vol. II, p. 155.

${ }^{13}$ Stapleton et al, "Chemistry in Irãq and Persia in the Tenth Century A. D.", Memoirs of the Asiatic Society of Bengal. VIII: 6, 1927, pp. 408-9.

${ }^{14}$ H. P. J. Renaud \& G. S. Colin (Orgs.), Tuhfat Al-Abbab-Glossaire de la matière Mèdicale Marocaine. (Paris, Librarie Orientaliste Paul Geuthner, 1934), pp.403 e 354. Plínio. op. cit., Livro XXXIV, Cap. 22 Dioscórides; The Greek Herbal of Dioscórides. reimp. (ilustrações bizantinas de 512; J. Goodyer, trad, ingl. de 1655; R. T. Gunther, $1^{\mathrm{a}}$ ed. e org. do texto ingl. 1933) (Nova York, Hafner Publishing, 1959), cf., V:84 e V:120; sobre o zinco metálico e a discussão entorno as suas origens e descoberta, vide H. E. Stapleton et al, "Chemistry...", loc. cit., pp. 323, 350, 408-9 e notas.

${ }^{15}$ Existe menção aos "elixires" no índice do L.T.A. (fl. 5r); mas esta é a primeira vez que o termo ocorre no receituário.

${ }^{16}$ L.T.A., fls $20 \mathrm{r} / \mathrm{v}$.

${ }^{17}$ Ibidem.

${ }^{18}$ Vide, por exemplo, [pseudo-] Ibn Sina em H. E. Stapleton et al, "Two Alchemical Treatises Attributed to Avicena” Ambix. X: 2 jun. de 1962, p. 67 e [pseudo-] Geber em Newman, The Summa Perfectionis of Pseudo-Geber, (Leyden/N. York, E.J. Brill, 1991), p. 673.

19 Op. cit., Livro XXXIV, Cap. 47.

${ }^{20}$ L.T.A. fl. 13 r. 
${ }^{21}$ L.T.A., fls $20 \mathrm{v}-21 \mathrm{r}$.

22 Vide especificação dos sete níveis de composição das naturezas em Kraus, Jabir ibn Hayyan: contribution à histoire des idées scientifiques dans l'Islam. reimp. (Bulletin de l'Institut d'Égypte, vol. 45, Cairo, 1942) (Paris, Belles Lettres, 1986), p. 173; correspondência em [pseudo-] al-Majriti, cf. D. Pingree, "Some of the Sources of the Ghayat al-Hakim", Jour. Warb. Cour. Inst., Vol. XLIII, 1980, p. 3.

${ }^{23}$ Sobre a primazia desses "espíritos", vide meu Livro do Tesouro de Alexandre, op. cit., em notas tradução ao texto, p. 129; sobre o princípio da similaritude na alquimia - ouro e prata como sementes de seus iguais - cf. Stapleton et al, "Alchemical...", loc. cit., p. 59 e nota 3; e "Two Alchemical...", loc. cit., p. 67, nota 65, que trata de diferentes alquimistas.

${ }^{24}$ L.T.A., fls $20 \mathrm{v}-21 \mathrm{r}$.

${ }^{25}$ L.T.A., fls $21 \mathrm{r} / \mathrm{v}$.

${ }^{26}$ H. E. Stapleton et al, "Chemistry...", loc. cit., p. 367, nota 7.

27 fls. $21 \mathrm{v}$ e $22 \mathrm{r}$.

28 cf. fl. 14 r.

29 R. C. Thompson, A Dictionary of Assyrian Chemistry and Geology, (Oxford, Clarendon Press, 1936), pp. XXXI et seq.

${ }^{30}$ Vide J. Gelb et al (Orgs.), The Assyrian Dictionary, Chicago, Oriental Institute/ J.J. Augustin, 1956, verbete "idru"; A. Debus, "The Significance of the History of Early Chemistry", Journ. World History, Vol. IX, 1965, p. 47, refere-se aos estudos em que K. W. Ganzenmüller associa a "pedra filosofal" ao vidro vermelho rubi.

${ }^{31}$ Vide Ruska, Al-Razi's.., op. cit., p. 76 et seq., sobre a variedade de elixires e suas potências de transmutação.

${ }^{32}$ Livro dos 70 do corpus jabiriano, vide ed. de P. Kraus, Textes choisis, Cairo, Inst. Franc. Arch. Orient., 1935, sobretudo p. 479 et seq.

33 cf. fl. $11 \mathrm{v}$.

${ }^{34}$ Vide seu "The Origins of the so-called "Theology of Aristotle", J. Kraye et alii, orgs., Pseudo-Aristotle in the Middle Ages, Londres, Warb. Inst., 1986, p. 111 e nota à p. 227.

35 Vide Estudo V, em meu Livro..., op. cit., p. 91 et seq..

${ }^{36}$ Como se sabe, o estudo de antigos textos prevê o levantamento de sua família documental (possíveis originais, cópias, variantes e compilações) e das prováveis fontes que lhe deram origem, como primeira etapa para sua tradução ou fixação e estabelecimento. Estes cuidados evitariam equívocos sobre sua datação, origens e possíveis transformações, pois dariam condições para comprovar as raízes e motivações dos temos, conceitos e ideias ali presentes. Sobre essa norma filológica tradicional vide, por exemplo: B. Spaggiari e M. Perugi. Fundamentos da crítica textual, (Rio de Janeiro: Lucerna, 2004); além da obra bem conhecida de S. Spina, Introdução à edótica - Crítica Textual. $2^{\mathrm{a}}$ ed., (São Paulo: Ars Poética/EDUSP, 1994.)

${ }^{37}$ Stapleton anuncia seus propósitos já em suas primeiras grandes memórias desde 1905, vide, por exemplo, "Sal-amoniac: a Study in Primitive Chemistry". Memoirs of the Asiatic Society of Bengal. $\mathrm{I}: 2,1905$.

${ }^{38}$ Esse pressuposto volta repetidas vezes a aparecer em seus trabalhos futuros,como os citados no início do presente estudo.

39 Stapleton, "The Antiquity of Alchemy", in Ambix, vol. 5, 1953; esse trabalho resume como nenhum outro as buscas frustradas e as expectativas desse estudioso.

${ }^{40}$ A principal diferença entre esses dois autores foi que Stapleton viveu na Índia e outras colônias orientais britânicas, consultando uma enorme mas esparsa documentação); enquanto Ruska teve como base os estudos e documentos deixados por orientalistas da famosa escola germânica que se desenvolveu em Berlim no século XIX; vide como exemplo a discussão de Ruska na Tabula Smaragdina. (Heidelberg, Carl Winter's University, 1926).

${ }^{41}$ J. Ruska. "Methods of Research in the History of Chemistry". Ambix. I: 1 (maio, 1937), pp. 21-9. 
${ }^{42}$ J. Ruska. Al-Razi's, op. cit.

${ }^{43}$ J. Ruska, Tabula, op. cit.cap. I.

${ }^{44}$ Vide, por exemplo, as discussões na obra de Thompsom citada acima.

45 Existem constantes referências a essa problemática em grandes tratados de história da química, como por exemplo, em J. R. Partington. A History of Chemistry, 4 vols., (Londres/Nova York, Macmillan/St. Martin's Press, 1970-1972) e 4 vols., (Londres/Nova York, Macmillan/St. Martin's Press, 1970-1972) e R. P. Multhauf. The origins of Chemistry. (Nova York, Franklin Watts, 1967)

${ }^{46}$ Vide, por exemplo, trabalhos como os de S. N. Kramer. "Sumerian Literature and the Bible". Studia Biblica et Orientia. III, 1959.

${ }_{47}$ Para uma breve revisão desses problemas vide, por exemplo, meus trabalhos sobre a história do salitre: A. M. ALFONSO-GOLDFARB, "As problemáticas fontes para uma história do salitre". In: XV Reunión internacional instituciones y personalidades trayectoria vital, 2005, Buenos Aires. Rihecqb historia y epistemología de las ciencias: XV reunión internacional instituciones y personalidades trayectoria vital. Buenos Aires : FEPAI, 2005. p. 1-6; e A. M.

ALFONSO-GOLDFARB. "Novas e velhas questões sobre o Salitre no séc. XVII através da Memória de N. Henshaw dedicada à Royal Society”. São Paulo: FAPESP/Livraria da Física. Colóquio CESIMA ano X, 2005.

48 W. Ganzenmuller. "Beitrage zur Geschichte des Goldrubinglases", Glastechnische berichte:1937, 15: 346-353; 379-384; 417-426.(em três artigos complementares e divididos, respectivamente, nos números de abril, outubro e novembro desse volume); a argumentação acima mencionada, encontra-se sobretudo no primeiro e terceiro artigo; vide também seus estudos em "Die Anschauungen vom Wesen des Glases...", Glastechnische berichte, :1938, 16: 358-365; 392-422.(em dois artigos complementares divididos, respectivamente, nos números de outubro e novembro desse volume).

49 A sugestão de repetir experimentos e demais procedimentos, indicados na documentação, pode ser facilmente encontrada na maioria das obras gerais em história da ciência (sobretudo nas partes dedicadas à ciência moderna), escritas até meados do século passado. Considerava-se esta como uma maneira ilustrativa de mostrar o avanço da ciência e até didática de ensiná-la. Embora estudiosos como Ruska e Stapleton nunca tenham feito esse tipo de sugestão, a visão que a sustentou (pautada num modelo de ciência moderna) permeia a obra de ambos, conforme pode ser visto ao longo dos trabalhos acima referidos.

${ }^{50}$ A. Debus, "The significance of the history of early chemistry", J. W. H., argumentação à p. 41 et seq.

${ }^{51}$ Ibid. p. 43.

52 Vide o clássico de A. Debus. The English Paracelcians. (New York: Franklin Watts, 1966).

53 Centro Simão Mathias de Estudos em História da Ciência/ PUC-SP.

${ }^{54} \mathrm{Na}$ última década, dois grandes projetos temáticos, apoiados pela Fundação de Amparo a Pesquisa do Estado de São Paulo e abrigados no CESIMA, foram subseqüentemente o esteio desse mapeamento, a saber: Revelando os processos Naturais Através do Laboratório: A busca por Princípios Materiais nos três Reinos até a Especialização das Ciências no Setecentos (2006-2010); As complexas transformações da ciência da matéria: entre o compósito do saber antigo e a especialização moderna (2000-2005). 